\title{
14-3-3 protein regulation of excitation-contraction coupling
}

\author{
Walter C. Thompson ${ }^{1} \cdot$ Paul H. Goldspink ${ }^{1}$
}

Received: 30 July 2021 / Revised: 21 October 2021 / Accepted: 23 October 2021 /Published online: 25 November 2021 (c) The Author(s) 2021

\begin{abstract}
14-3-3 proteins (14-3-3 s) are a family of highly conserved proteins that regulate many cellular processes in eukaryotes by interacting with a diverse array of client proteins. The 14-3-3 proteins have been implicated in several disease states and previous reviews have condensed the literature with respect to their structure, function, and the regulation of different cellular processes. This review focuses on the growing body of literature exploring the important role 14-3-3 proteins appear to play in regulating the biochemical and biophysical events associated with excitation-contraction coupling (ECC) in muscle. It presents both a timely and unique analysis that seeks to unite studies emphasizing the identification and diversity of 14-3-3 protein function and client protein interactions, as modulators of muscle contraction. It also highlights ideas within these two well-established but intersecting fields that support further investigation with respect to the mechanistic actions of 14-3-3 proteins in the modulation of force generation in muscle.
\end{abstract}

Keywords $14-3-3$ proteins $\cdot$ Muscle $\cdot$ Excitation-contraction coupling

\section{Introduction}

Investigations into the function of 14-3-3 proteins over the last 30 years have elucidated their role in the regulation of several cellular pathways, including but not limited to, signal transduction, protein trafficking, cell cycle regulation, apoptosis, and metabolism. They operate as homodimers and heterodimers with each monomer capable of binding to phosphorylation sites within 14-3-3 binding motifs on client proteins. In general, there are two predominant binding motifs that have been identified, mode I and mode II each with consensus sequences defined as $\mathrm{R}(\mathrm{S} / \mathrm{X}) \mathrm{XpSXP}$ and $\mathrm{RXXXpSXP}(\mathrm{X}$ is any amino acid residue and $\mathrm{p}$ is adjacent to a phosphorylated serine or threonine) respectively [72]. A third consensus sequence $\left(\mathrm{pS} / \mathrm{pTX}_{1-2}-\mathrm{COOH}\right)$ later identified appears to bind 14-3-3 proteins with a weaker affinity, although other binding motifs have been identified and the binding to unphosphorylated sites on some proteins is also recognized $[15,20,29]$. Once bound, they generally

Paul H. Goldspink

pgolds@uic.edu

1 Department of Physiology and Biophysics (M/C 901) and Center for Cardiovascular Research, College of Medicine, University of Illinois at Chicago, 835 South Wolcott Avenue, RM E-202, Chicago, IL 60612, USA modulate client protein activation, inhibition, structural stabilization, masking of sites, and intracellular localization [47].

Phylogenetic analysis indicates 14-3-3 proteins evolved in unicellular and multicellular eukaryotes before the divergence of mammals. They exhibit a high degree of homology between the various isoforms of the same species, suggesting conservation of critical regions and function [53]. The high level of conservation of core regions and X-ray crystallographic studies of the mammalian isoforms has permitted identification of 3D structural features which are applicable to all the isoforms [73]. The $\sim 30-\mathrm{kDa}$ monomers consist of 9 antiparallel arranged $\alpha$-helices (H1-9), forming an L-shape structure. Helices 3, 5, 7, and 9 form a highly conserved amphipathic grove on the inner surface of all the isoforms which forms the site of ligand binding on client proteins. The formation of homodimers and heterodimers occurs between highly conserved sequences in the $\mathrm{N}$-terminus of helix 1 on one monomer, and helices 2 and 3 on the opposing monomer. The conserved nuclear export signal in helix 9 supports nuclear shuttling activities in addition to the established roles of the dimers acting as adaptors binding two different client proteins or two different regions of the same protein.

In humans, the seven isoforms $(\beta, \varepsilon, \eta, \gamma, \theta, \zeta$, and $\sigma)$ are encoded by separate genes (YWHAB, YWHAE, YWHAH, YWHAG, YWHAQ, YWHAZ, and SFN or Stratifin) and 
are expressed in a wide variety of tissues to varying degrees. Based on transcriptomic data in The Human Protein Atlas database, the 14-3-3 isoform-specific RNA expression profiles differ between the muscle subtypes and are summarized in Fig. 1. The data examining human 14-3-3 isoform-specific protein expression levels in the muscle subtypes are far less clear, with some isoforms not detectable. However, this may reflect limitations in the tools available to examine isoform-specific protein expression as opposed to the abundance of probe sets or sequence identification used in transcriptomic approaches. The regions of greatest protein sequence variability appear in the amino and carboxylterminal regions of the isoforms. The $\mathrm{N}$-terminal region is responsible for dimerization and sequence variations here may underly the differing propensity of the isoforms to form homodimers or heterodimers [73]. Sequence variations in the C-terminus have been speculated to function in an isoform-specific autoinhibitory capacity during ligand binding, through a conformation change when phosphorylated [48]. Several excellent reviews have focused more extensively on 14-3-3 structure and function, their actions in modulating of cellular signaling, and the development of compounds to alter their activities, and are recommend for further reading $[43,47,59,71]$.

While 14-3-3 protein structure and function have been extensively studied in a vast array of non-muscle eucaryotic cells, the number of muscle-specific studies is limited. A recent PubMed search using the terms "14-3-3 AND muscle" identified 273 studies. Based on commonly used keywords listed, most of these studies examine 14-3-3 modulation of signaling pathways leading to transcriptional changes, apoptosis, autophagy, endoplasmic reticulum (ER) stress, cell cycle regulation, and mitochondrial function. In the case of smooth muscle, studies examining cell migration and cytoskeletal reorganization are also represented. On a

\section{4-3-3 Isoform RNA Expression Overview}

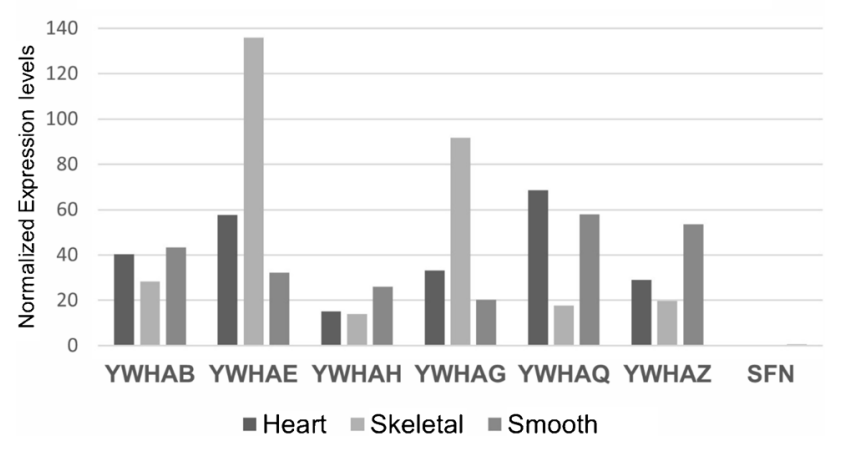

Fig. 1 Human 14-3-3 isoform RNA expression in different muscle subtypes. Curated data from The Human Protein Atlas consensus dataset (www.proteinatlas.org). It represents expression levels from combined transcriptomic datasets that are normalized to 55 different tissues and 6 cell lines broader scale, 14-3-3 proteins have been also implicated in organ development, muscle growth/hypertrophy, muscle differentiation, substrate uptake, and metabolism. However, the purpose of this review is to summarize emerging studies examining the interaction of 14-3-3 proteins with the proteins associated with excitation-contraction coupling (ECC) and in some cases, aligning their function with signaling events associated with its regulation. Moreover, from the prospective of a greater understanding of ECC and its regulation, there is little recognition of the role of 14-3-3 proteins in this process in general. Consequently, we aim to draw attention to this area through the assembly of a body of literature and discuss the potential mechanistic implications for 14-3-3 regulation of muscle contractile function.

\section{Modulation of 14-3-3 expression and genetic manipulation of function in muscle}

Studies examining the regulation of 14-3-3 expression have predominantly characterized changes in their expression profile with respect to injury or disease, but surprisingly none has investigated the molecular regulation of 14-3-3 gene transcription per se. The proliferation of vascular smooth muscle cells (VSMC) in response to vascular injury contributes to vascular restenosis. In the carotid artery following balloon angioplasty in rats, 14-3-3 $\gamma$ RNA expression increases within $24 \mathrm{~h}$ in the vessels. In cultured VSMC following serum, proinflammatory cytokine, and mitogenic stimulation, increases in 14-3-3 $\gamma$ RNA expression occur within $2-3 \mathrm{~h}$ and protein increases occur within 8-16 h [6, 7]. A possible translational corollary associated with these observations is indicated in patients diagnosed with coronary artery vasculopathy which is associated with cytokineinduced activation and proliferation of medial VSMC as a critical cellular event in restenosis. Compared to patients with end-stage heart failure, coronary artery samples show elevated 14-3-3 $\gamma$ protein expression which colocalizes histologically with smooth muscle $\alpha$-actin in the media and neointima of the vessel [5]. Although most isoforms are expressed at low levels in many tissues, $14-3-3 \gamma$ appears to be expressed at higher levels in human brain, skeletal muscle, and heart compared to other tissues [6,7]. Similarly, $14-3-3 \varepsilon$ appears to be expressed at higher levels in the human heart and skeletal muscle compared to other tissues and its expression peaks during late stages of embryonic development through neonatal life in the rodent heart [41]. Oxidative stress associated with taurine deficiency and streptozotocin-induced diabetes appears to induce the expression of 14-3-3 $\sigma$ in isolated cardiac myocytes, which is otherwise undetectable, but may play a role in cell cycle arrest in concert with DNA damage and cell death [23, 24]. Myocardial 
injuries associated with severe burn and sepsis induce 14-3$3 \gamma$ and $\eta$ expression changes within the first $12 \mathrm{~h}$ post-injury

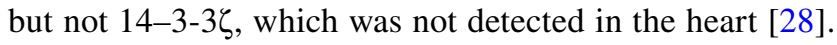
Interestingly, a study modeling age-associated heart failure in the senescence accelerated prone mouse (SAMP8), 14-3-3 $\eta$ protein expression in the heart trended lower than the normal aging control, and was associated with cardiac dysfunction, dysregulation of markers of ER, myocyte DNA damage, and expression of pro-inflammatory cytokines [57].

Neonatal rat cardiac myocytes (NRVM) are extensively used as an in vitro model to examine aspects of myocyte biology and the expression of 14-3-3 $\beta, \gamma, \varepsilon$, and $\zeta$ isoforms can be detected at both RNA and protein levels. The expression of 14-3-3 proteins does not appear to change in response to norepinephrine (NE)-induced hypertrophy. However, inhibition of their activity via adenoviral mediated delivery of a 14-3-3 inhibitor (R18, a 20-mer peptide) is sufficient to induce and potentiate NE-stimulated protein synthesis, suggesting 14-3-3 proteins may suppress hypertrophic signaling pathways [38]. Similarly, $14-3-3$ protein expression increases over a 12-24-h time-course in NRVM exposed to anoxia preconditioning as an in vitro model of late-stage ischemic preconditioning in the heart, but the response of specific 14-3-3 isoforms here was not studied [12]. Likewise, in anoxia-reoxygenation injury in $\mathrm{H} 9 \mathrm{c} 2$ cells often used as a "cardiac-like" cell line, knockdown of sirtuin (SIRT2), a signaling protein involved in stress-tolerance, results in increased $14-3-3 \zeta$ protein levels implicating an involvement in cytoprotective signaling [42].

Proteomics-based approaches have helped to further define 14-3-3 isoform expression in muscle tissues. 14-3-3 $\gamma$ protein expression in the corporal smooth muscle cells of the corpora cavernosa has been shown to increase within days following streptozotocin-induced diabetes [74]. Likewise, quantification of 14-3-3 protein isoform abundance identified $14-3-3 \varepsilon, \gamma, \eta, \theta$, and $\zeta / \sigma$ in differentiated $\mathrm{C} 2 \mathrm{C} 12$ cells and mouse triceps, with greater levels of $14-3-3 \gamma, \eta$, and $\theta$ in the skeletal tissues compared to the other isoforms [16]. Analysis of 14-3-3 protein expression changes through the incorporation of isobaric tags and mass spectrometry analysis used to examine the tibialis anterior muscle proteome following sciatic nerve transection identified increased 14-3-3 $\beta, \gamma, \varepsilon$, and $\zeta$ abundance during the first week of denervation [60]. Since most studies have focused on 14-3-3 protein function in the modulation of transcriptional programs, very few have focused on 14-3-3 genes as targets of transcriptional regulation in the context of muscle growth. Examining the regulatory role of microRNAs (miRNA) during skeletal muscle myogenesis, ectopic expression of miR-34b, and quantitative proteomic analysis confirmed the downregulation of 14-3-3 $\gamma$ occurred as a direct target of miR$34 \mathrm{~b}$ suppression via binding to the 14-3-3 $\gamma$ mRNA 3'UTR [61]. Likewise, the transcriptional modulation of $14-3-3 \gamma$ and other cell cycle checkpoint genes in proliferating skeletal myoblasts may be associated with silencing the activity of the transcription factor MEF2C, which is normally most active during the terminal differentiation stages in myogenesis [8].

One of the earliest studies testing 14-3-3 function in muscle expressed a dominant-negative form of $14-3-3 \eta$ in the heart. Dominant-negative 14-3-3 mutant forms were first

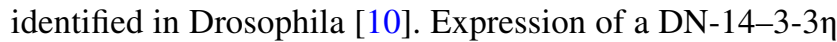
transgene in cardiac myocytes demonstrated the necessity of 14-3-3 function in preserving cardiac function and sur-

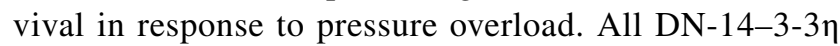
transgenic mice died within 7 days of transverse aortic constriction [70]. Follow-on studies utilizing this DN-14-3-3n model have subsequently demonstrated the role of $14-3-3 \eta$ in mediating apoptotic signaling intermediaries in response to pressure overload, diabetes, ventricular remodeling, and oxidative stress, and collectively implicate that enhanced 14-3-3 expression or activity may provide a therapeutic benefit in several cardiac disease states [25, 26, 54, 62, 68, 75].

Studies employing germ-line deletion of the 14-3-3 isoforms were mainly developed for the purpose of studying neurological defects associated with each isoform. However, they have provided somewhat conflicting data with respect to the necessity 14-3-3 isoform expression for survival and ability to thrive, in large part due to the influence of background strain and knockout strategies used. Originally, deletion of 14-3-3e allele resulted in heterozygous mice that were normal and fertile. Breeding these mice to homozygosity mainly produced mice that then die within hours of birth, but with only a small percent surviving to adulthood if bred on a mixed background compared to original inbreed strain [64]. Examination of possible causality of premature death during embryonic development of the 14-3-3e-deficient mice on the inbred strain revealed that $14-3-3 \varepsilon$ expression in the cardiac myocytes was required for normal ventricular morphogenesis and compaction of the myocardium. Interestingly, expression of the other 14-3-3 isoforms did not change or compensate for the lack of 14-3$3 \varepsilon$, indicating a level of isoform specificity in the developing heart [34]. In a follow-on and more detailed study of the cardiac malformations resulting from $14-3-3 \varepsilon$ deletion, defects in the outflow tract, atrioventricular endocardial cushions, valvular, and vasculature were all apparent during mid and late gestion indicating the necessity of $14-3-3 \varepsilon$ to control multiple aspects of cardiac development [22]. Similarly, deletion of $14-3-3 \theta / \tau$ results in death during embryonic development of homozygous embryos with indications of delayed cardiac development, but with otherwise a normal morphologic appearance. Interestingly, haploinsufficient offspring are viable with normal cardiac function, but show an enhanced rate of mortality and increased cardiac myocyte apoptosis following coronary artery ligation [36]. Deletion 
of 14-3-3 $\gamma$ by insertion of the neomycin gene into exon 2 on an inbred background did not produce any obvious phenotypic alterations despite initial gene copy number and offspring being born with the expected Mendelian frequency [58]. However, deletion of 14-3-3 $\gamma$ using gene trapping to insert $\beta$-galactosidase into exon 2 to produce a truncated protein with just the $3 \mathrm{~N}$-terminal $\alpha$-helical domains intact produced homozygotes that all died by weaning [32]. Mice deficient in 14-3-3 $\zeta$ also generated by gene trapping and maintained as heterozygous breeders on an inbred background or a mixed background appear viable and phenotypically indistinguishable to their wild-type littermates [11]. Thus, except for $14-3-3 \theta / \tau$, no other studies have been conducted to examine the impact on 14-3-3 isoform haploinsufficiency in response to a perturbation in the muscles of these models, and none has examined muscle-specific 14-3-3 deletion.

\section{4-3-3 modulation of muscle membrane channels, exchangers, and pumps}

The fundamental function of muscle tissue is to generate force which is initiated by the process of ECC. ECC is the progression of molecular events which start with changes in the resting membrane potential of the sarcolemma resulting in an action potential. The depolarization phase of the action potential generates a rise in the intracellular calcium which binds to a calcium sensor protein, permitting the interaction of myosin with actin and the generation force. This finely orchestrated multi-step process is regulated at various levels and differs between muscle subtypes. The changes in electrophysiological state of the sarcolemma through movement of different ions across the membrane facilitated by channels and pumps generally represent the first level of regulation. The function of 14-3-3 proteins in this aspect of muscle physiology is varied ranging from membrane channel chaperonin partners, aiding channel subunit assembly to modulators of channel and pump activities. In the context of 14-3-3 protein-mediated channel trafficking from the Golgi to the cell membrane, a description of the steps involved has been the focus of an excellent review [56], but the broader physiological implications, 14-3-3 protein interactions with these client proteins in the context ECC, are highlighted in the studies below.

Voltage-gated sodium channels are responsible for initiation and propagation of the action potential. These channels are composed of a transmembrane $\alpha$-subunit which has four repeat domains and forms the pore (I to IV), plus accessory $\beta$-subunits. $14-3-3 \eta$ interactions with the cytoplasmic region of the $\alpha$-subunit interdomain I were first identified by a yeast 2-hybrid screen and validated biochemically [1]. Similar interactions with $14-3-3 \theta / \tau$ and $\zeta$ were also identified, and
14-3-3 $\eta$ was shown colocalized with the $\mathrm{Na}^{+}$channel to the intercalated disc in cardiac myocytes. Functionally, the presence of 14-3-3 $\eta$ did not change channel activation or current density but altered channel inactivation in a heterologous cell system, which required in part 14-3-3 protein dimerization. Further examination of 14-3-3 protein interactions with the $\mathrm{Na}^{+}$channel has shown they may support the formation of $\alpha$-subunit dimers harboring mutations linked to cardiac arrhythmias. Inhibiting the 14-3-3 interaction abolished the dominant negative effect on current amplitude of the mutant channels. Binding site analysis indicated that 14-3-3 binding did not play a direct role in channel dimerization but altered gating properties [14]. While a second 14-3-3 binding site was identified in the interdomain I cytoplasmic loop in addition to the previously reported site, which 14-3-3 isoforms and their dimerization state in bridging these sites to account for the altered gating properties of these channels have yet to be defined.

The inward rectifier $\mathrm{K}^{+}$current carried by the Kir2.1 channel reestablishes and maintains the resting membrane potential in cardiac muscle cells. While the function of these channels' contrasts with that of the $\mathrm{Na}^{+}$channels, a pool of these two channels appears to be trafficked to the membrane. There they exist in multiprotein complexes and reciprocally modulate each other's channel density. Inhibiting 14-3-3 protein interactions does not appear to impact individual channel densities but abolished reciprocal modulation of the complex without altering the formation of the complex in the membrane [66]. Interestingly, it is proposed that disruption of anterograde trafficking of the $\mathrm{Na}^{+}$channel via 14-3-3 protein interaction inhibition may occur within the same region of the interdomain I cytoplasmic loop initially identified to contain PKA phosphorylation and ER retention motifs, and subsequently identified to contain 14-3-3 binding sites [40, 76]. A similar proximity and potentially functionally overlapping area of ER retention and 14-3-3 binding motifs has also been recognized in the pore-forming subunit of the voltage-gated calcium channel Cav2.2, predominantly expressed in presynaptic nerve terminals. Here it was shown to play a role in membrane trafficking of the pore-forming subunit independently of the auxiliary subunits, through $14-3-3 \theta / \tau$ binding and masking the ER retention signal thereby allowing the channel to escape the ER [37]. The co-existence and interplay between ER retention motifs recognized by the COPI complex of the retrieval pathway of protein containing vesicles from the cis-Golgi membrane to the ER, and 14-3-3 binding motifs required to reach the cell surface, were studied in the trafficking and assembly of the metabolically sensitive ATP-sensitive $\mathrm{K}^{+}\left(\mathrm{K}_{\mathrm{ATP}}\right)$ channel complex in the heart [4]. Utilizing knockout mice deficient in the pore forming subunit (Kir6.2), the sulfonylurea receptor subunit (SUR1), which contains ER retention signal, was shown to be retained intracellularly localized to the Golgi in the 
ventricular myocytes. $\beta$-adrenergic receptor agonists stimulated the translocation of SUR1-containing $\mathrm{K}_{\mathrm{ATP}}$ channel, and increased SUR1, Kir6.2, and 14-3-3 phosphorylation, indicating 14-3-3 protein interactions control anterograde trafficking needed to overcome COPI-dependent retrieval signaling.

Activation of the delayed rectifier channels carries the $\mathrm{K}^{+}$current and modifies the rate of membrane potential repolarization during the action potential. The ether-a-gogo-related gene $(H E R G)$ encodes the pore-forming subunit of the channel permitting the delayed rectifier $\mathrm{K}^{+}$current $I_{\mathrm{Kr}}$, responsible for the rapid phase of depolarization. Binding of $14-3-3 \varepsilon$ enhances voltage-dependent activation in the negative voltages ranges in $\mathrm{CHO}$ cells that could result in a faster current activation during cardiac action potentials. This functional effect occurs through direct 14-3-3 protein cross-bridging and stabilization of the PKA phosphorylated state of the channel, which appears to involve two sites $(\mathrm{N}-$ and C-terminal site) [30]. The pathophysiological significance of 14-3-3 protein modulation of HERG channel properties was highlighted in the analysis of naturally occurring C-terminal truncation mutations in heterozygous families with long-QT syndrome (LQTS) [13]. These channels are an assembly of four $\alpha$-subunits each composed of cytoplasmic $\mathrm{N}$ - and C-terminal domains, and six transmembrane segments. C-terminal truncation mutated channels, in which the PKA phosphorylation, 14-3-3 binding sites, and ER signal are removed, can still bind $14-3-3 \varepsilon$ and assemble as functional channels in the membrane. However, mutant channels do not respond to hyperpolarized membrane potentials and display dominant-negative behavior when co-expressed with wild-type channels in $\mathrm{CHO}$ cells. While not studied directly in cardiac myocytes, modeling of this HERG channel activity on the action potential duration in response to sympathetic stimulation indicated 14-3-3 protein interactions may be important in suppressing arrhythmias arising from premature ectopic beats in patients with LQTS due to C-terminal channel truncation mutations. Exploring HERG channel $14-3-3 \varepsilon$ interactions in the context of $\beta$-adrenergic modulation indicated that the $\beta_{1}$-adrenergic receptor competes with the HERG pore-forming subunit for 14-3-3 $\varepsilon$ both in the presence and absence of receptor stimulation. $\beta_{1}$ adrenergic receptor competition for 14-3-3e, and complex formation, appears to be directly occurring through PKA phosphorylation of putative 14-3-3 binding sites within the receptor and can be decreased by $\beta$-receptor antagonist treatment. Studying these interactions in heart samples, the $\beta$-receptor/14-3-3e complex coeluted to a greater extent following stimulation [65]. In studying the functional consequences on the HERG channel, current modulation following $14-3-3 \varepsilon$ recruitment to the PKA phosphorylation sites identified in the cytoplasmic domain of the $\beta$-receptor showed that phosphorylation-deficient mutants did not associate with $14-3-3 \varepsilon$ which abolished $\beta$-receptor modulation of the HERG channel current. Finally, investigation of drug interactions with mutant HERG channels in LQTS using patient-specific human-induced pluripotent stem cell-derived cardiac myocytes (hiPSC-CMs) implicated that peroxisome proliferator-activated receptor-delta (PPARס) agonists may exert indirect effects on mutant HERG channel activity by inducing 14-3-3 $\varepsilon$ expression changes, but no direct data in support of this role was investigated [19].

While the literature surrounding 14-3-3 protein interactions with membrane channels probably represents the most in-depth area of investigation with respect to their functional role in modulating ECC, studies examining 14-3-3 interactions with membrane pumps and exchangers which contribute to ion homeostasis in muscle cells also provide examples of their influence. The $\mathrm{Na}^{+} / \mathrm{K}^{+}$-ATPase, an electrogenic pump which creates a gradient of $\mathrm{Na}^{+}$and $\mathrm{K}^{+}$across the plasma membrane to establish a resting membrane potential, is of note. The $\mathrm{Na}^{+} / \mathrm{K}^{+}$-ATPase activity increases during cardiac ischemia and adrenergic stimulation via the phosphorylation of a 72 amino acid accessory protein called phospholemman, which regulates $\mathrm{Na}^{+}$pump function. Phospholemman's interaction with $14-3-3 \beta$ is increased during ischemia and in isolated cardiac myocytes following direct PKA activation but is abrogated by expressing a mutant 14-3-3 $\beta$ (K49Q) [21]. Likewise, 14-3-3 $\beta$ binding to the $\mathrm{Na}^{+} / \mathrm{H}^{+}$exchanger (NHE) which regulates intracellular $\mathrm{pH}$ and mediates increases in exchanger activity during ischemia/reperfusion injury through phosphorylation of NHE1 by p90RSK. Uncoupling the 14-3-3/NHE interaction via overexpression of dominant-negative RSK in the heart was found to be beneficial and limited cell death [45].

\section{Calcium homeostasis}

The rise in cytosolic calcium levels is the trigger for contraction in all type of muscles. The management of the intracellular calcium concentration reflects the balance of calcium influx and release from intracellular stores, verses its reuptake into stores and extrusion out of the cytosol. 14-3-3 proteins have been identified to interact with some of the exchangers and pumps that play an integral role in the maintenance of calcium homeostasis.

The plasma membrane $\mathrm{Na}^{+} / \mathrm{Ca}^{2+}$ exchanger and $\mathrm{Ca}^{2+}$-ATPase pump both function to remove and transport $\mathrm{Ca}^{2+}$ ions from the cytosol into the extracellular space. While different isoforms exist, both are enriched in muscles and have been shown to be modulated by 14-3-3 proteins. In the framework of $\mathrm{Na}^{+} / \mathrm{Ca}^{2+}$ exchanger interactions, the NCX2 isoform which is predominantly expressed in the brain was identified to interact with $14-3-3 \varepsilon$ and $\zeta$ which produced an inhibitory effect on NCX2 function. Extending 
these observations to the NCX1 and NCX3 isoforms which are predominantly expressed in muscle, a similar inhibition of exchanger function was noted. Specifically, the binding of $14-3-3 \varepsilon$ reduced the exchanger's ability to clear stimulated increases in intracellular $\mathrm{Ca}^{2+}$, which occurred independently of changing NCX levels in the membrane and NCX phosphorylation [51]. Of the different plasma membrane $\mathrm{Ca}^{2+}$-ATPase pump (PMCA) isoforms that exist, the ubiquitously expressed PMCA1 and PMCA4 isoforms are expressed in muscle. Despite their wide tissue distribution, their functional properties are modulated in part by various partner proteins. These proteins interact with the different intracellular domains of the pump of which the N-terminal domain has the lowest sequence homology between the isoforms. Focusing of N-terminal domain interacting partners to assign PMCA isoform specificity, the binding of 14-3-3e to this region in PMCA4 but not PMCA2 occurs independently of phosphorylation and inhibits the pump's ability to export $\mathrm{Ca}^{2+}$ which is rescued by silencing $14-3-3 \varepsilon$ gene expression. Interestingly, the $\mathrm{N}$-terminal domain of PMCA4 does not appear to interact with $14-3-3 \theta$ and $\zeta$ isoforms based on their expression profile in HeLa cells possibly implying a level of 14-3-3 isoform target specificity, but the remaining isoforms were not tested [52]. Expanding the study of 14-3-3 interactions with PMCA1 and PMCA3, both pumps were found to interact with $14-3-3 \varepsilon$ whereas PMCA3 also interacted with 14-3-3ל. In this instance, testing all the other 14-3-3 isoforms against these two client proteins supported the notion that $14-3-3 \varepsilon$ is specific for PMCA1 in HeLa cells. Functionally, both pumps were also found to inhibited by 14-3-3 interactions in the N-terminus [39]. Sequence analysis of the $\mathrm{N}$-terminal region revealed that despite a conserved putative 14-3-3 binding motif present in all four PMCA isoforms, the predicted secondary structure of an adjacent $\alpha$-helix in PMCA2 differed and may contribute to the destabilization of the 14-3-3 interaction noted with this isoform.

Probably the most compelling examination of 14-3-3 protein function in the context cardiac muscle ECC is the recognition that 14-3-3 proteins interact with Phospholamban (PLN) [46]. PLN associates with the sarcoplasmic reticulum $\mathrm{Ca}^{2+}$-ATPase pump (SERCA) to negatively regulate SERCA activity and limit the kinetics of $\mathrm{Ca}^{2+}$ uptake into the SR. Phosphorylation of serine 16 on PLN by PKA following $\beta$-adrenergic stimulation and threonine 17 by $\mathrm{Ca}^{2+}$-calmodulin-dependent kinase II removes the inhibitory effects of PLN on SERCA, increasing $\mathrm{Ca}^{2+}$ uptake and accelerating relaxation of the contractile apparatus. Leveraging prior appreciation of the interaction between Arg-Arg ER retention motifs recognized by the COPI complex and 14-3-3 binding motifs for assembly and trafficking of channels, the existence of these adjacent sequences in the N-terminus of PLN was investigated [46]. Through a series of biochemical approaches to test the existence of protein-protein interactions, PLN pentamers were captured using 14-3-3 protein pull-downs, proximity labeling experiments in neonatal cultured myocytes, and immunoprecipitation data supported evidence of a direct interaction. Moreover, the affinity of 14-3-3 to bind to PLN monomers, and the avidity of the monomers to form pentamers, was dependent on Ser 16 and Thr 17 phosphorylation. Physiologically, the 14-3-3 protein interaction with PLN was promoted following $\beta$-adrenergic stimulation and shown to slow the kinetics of PLN dephosphorylation by masking the phosphosite on PLN. Functionally, the time constant of the $\mathrm{Ca}^{2+}$ transient decay was shown to be prolonged following acute $\beta$-adrenergic stimulation in the presence of recombinant $14-3-3$ protein, dialyzed into the adult myocytes. Thus, the 14-3-3 protein interactions with PLN serve to stabilize the phosphoform and disinhibit its effect on SERCA activity. Interestingly, the authors also point to a clinical corollary that may exist in patients carrying a mutation which results in the loss of Arg 14, adjacent to the 14-3-3 binding site at Ser16. These patients develop an aggressive dilated cardiomyopathy and genetically engineered mice recapitulating this myopathy suffer premature death, highlighting a pathophysiologic consequence associated with the disruption of the 14-3-3/PLN interaction.

\section{The contractile apparatus}

The contractile apparatus of muscle performs the fundamental role of generating force in response to a suitable stimulus. While elevated levels of intracellular calcium trigger the contractile response, differences exist in the calcium sensor which initiates the molecular events that culminate in crossbridge formation between the muscle subtypes. With the recognition of effector proteins 14-3-3 proteins interact with to modulate ECC, these studies point towards a more diverse role beyond the regulation of signaling pathways in muscle. However, only a few studies exist with respect to 14-3-3 proteins and the modulation of muscle contractile system. These studies mainly focus on 14-3-3 proteins in regulating upstream kinases and phosphatases that directly regulate contractile proteins to alter their function, or events associated with cytoskeletal rearrangement impacting contractile function, and are highlighted below.

In an effort to identify substrates of various protein kinases in skeletal muscle, phosphorylation of the skeletal myosin light chain kinase (MLCK) at Serine 16 was identified as a target for an upstream kinase [27]. MLCK phosphorylation of myosin light chain (MLC) plays a central role in the formation of the actin-myosin crossbridge in smooth muscle and modulates crossbridge function in cardiac and skeletal muscle. Phosphorylation of MLCK at 
Ser16 is associated with MLCK autophosphorylation and is increased during tetanic muscle contraction. Phosphorylation of Ser 16 was shown to induce binding of 14-3-3 proteins but it does not appear to change MLCK activity [27]. However, while MLC phosphorylation is central to crossbridge formation in smooth muscle, equally important is MLC dephosphorylation by myosin light chain phosphatase (MLCP), to initiate muscle relaxation. MLCP is composed of 3 subunits, of which the myosin phosphatase targeting subunit (MYPT1) binds the enzyme to myosin. MYPT1 can be directly phosphorylated to alter its affinity for myosin and increase the phosphatase activity of the catalytic subunit, but also change its intracellular localization. In regulating these activities, biochemical studies have identified $14-3-3 \beta$ to directly bind to MYPT1 to induce its dissociation from smooth muscle myosin, attenuate MLCP phosphatase activity, and alter its cellular localization [33]. $14-3-3 \beta$ bound to the region surrounding Ser472 on MYPT1 results in increased MYPT1/14-3-3 $\beta$ binding upon MYPT1 phosphorylation and an associated increase in MLC phosphorylation, suggesting a mechanism by which contraction maybe sustained or augmented may exist due to the interaction of 14-3-3 proteins with MYPT1.

The control of smooth muscle tone and vascular diameter involves not only the balance of myosin-light chain phosphorylation and dephosphorylation, but additional mechanisms related to the dynamics of cytoskeletal reorganization. The cytoskeleton anchors the contractile apparatus to the extracellular matrix and contributes to the contractile response to vasoactive stimulation. 14-3-3 proteins interact with proteins involved in the regulation of actin filament dynamics, but their interactions with cofilin have gained significant attention with respect to the regulation of smooth muscle contractile function. Cofilin is an actin regulatory protein that binds to the side of F-actin to promote actin filament disassembly and recycling of actin monomers during cytoskeletal remodeling. Involved in mediating the cofilin/Factin interaction is the small heat shock protein 20 (HSP20), also known as HSPB6. While the precise mechanism is still unclear, it is proposed that HSP20-mediated smooth muscle relaxation in response to elevated cyclic nucleotides results in HSP20 phosphorylation which displaces cofilin from its complex with 14-3-3 [17]. This hypothesis is based in part on the ability of a transducible recombinant phosphopeptide analog corresponding to 14-3-3 binding sequence surrounding Ser16 in HSP20, which has been shown to relax smooth muscle in various tissues, to disrupt the actin cytoskeleton, interact with 14-3-3 proteins, and dephosphorylate cofilin in cells. A comprehensive analysis of the 14-3-3 and HSP20 interaction showed that phosphopeptides derived from the N-terminus of HSP20 containing the site surrounding Ser16 interacted with and stabilized 14-3-3 proteins impeding their proteolysis [55]. The authors also explored the chaperoning activity of $14-3-3 \zeta$ monomers and dimers to prevent myosin $\mathrm{S} 1$ fragment aggregation subjected to increasing temperature. Compared to its homodimer and HSP20, the 14-3-3 $\zeta$ monomer was the most effective in preventing $\mathrm{S} 1$ fragment aggregation, suggesting that 14-3-3 proteins may target myosin as a client protein to alter its properties. Extending this interaction, it has been shown that human 14-3-3 $\sigma$ directly interacts with the tail fragments of purified human non-muscle myosin IIA-C fusion proteins to alter their assembly kinetics independent of phosphorylation [69]. Examination of the direct interaction between the 14-3-3 isoforms and the non-muscle myosin isoforms revealed they all interacted to varying degrees, but collectively suggests that 14-3-3 proteins may have a direct role regulating cellular mechanics at the level of the contractile proteins. Intriguingly, modulating the molecular interaction between Hsp20 and 14-3-3 proteins has formed the basis of a high-throughput screen for the discovery of small molecule analogs of phosphorylated HSP20 that may provide a therapeutic regiment for the treatment of smooth muscle vasospasm in lung diseases [2].

In cardiac myocytes, the cytoskeleton plays an important role in maintaining and anchoring the sarcomere and contributes to the overall tension development. Cytoskeletal rearrangements involving HSP20/14-3-3 and cofilin/14-3-3 protein interactions influencing actin cytoskeletal dynamics may have implications in the pathogenesis of heart failure. Treatment of cardiomyocytes with the HSP20 phosphopeptide which displaces cofilin from 14-3-3 proteins promotes actin filament disassembly, increased shortening and relaxation rates and the time constant of the $\mathrm{Ca}^{2+}$ transient decay [49]. Interestingly patients with a Hsp20 mutation P20L, which forms part of the 14-3-3 protein binding site surrounding Ser16, develop a dilated cardiomyopathy. Examining the impact of the human Hsp20-P20L mutation, it was shown this mutation conferred a diminished physical interaction with 14-3-3 proteins and failed to compete for 14-3-3 binding to cofilin upon phosphorylation [67]. Consequently, this mechanism may be sufficient to influence contractile dynamics directly or indirectly via modulating the cytoskeletal reorganization that are mediated through changes in the state of F-actin polymerization.

\section{How 14-3-3 interactions combine to modulate ECC in health and disease}

Without a clear indication as to necessity of 14-3-3 proteins in the modulation for ECC through muscle-specific deletion, speculation based on the literature presented herein and in other electrically excitable tissues does suggest their dysregulation may contribute to disease state. 14-3-3 proteins have been implicated in neurodegenerative and neuropsychiatric 
diseases and are highly expressed in the brain, making up about $1 \%$ of the total soluble brain protein [9]. In the context of ECC, the literature at present points towards three main areas which are summarized in Fig. 2. These are the regulation of electrophysiologic properties, regulation of calcium homeostasis, and modulation of contractile function, but with fewer studies existing in support of the later. Their role in the protein-protein interactions associated with voltagegated channel assembly, modulation of current properties in response to physiological stimulation and membrane trafficking in the formation of channel complexes, all point to their need in maintaining the normal electrophysiologic state of the muscle cell membrane. Simulations modeling the effect of 14-3-3 loss-of function on the action potential indicate their absence may be proarrhythmogenic but this has not been tested directly. However, their involvement in the assembly of mutant channel subunits implicated with inherited arrhythmias indicates they play an indirect role in disease development via the assembly of dysfunctional client proteins. These data and those showing their regulation of ionic gradients by modulating the activity of membrane pumps and exchangers all coalesce around the notion 14-3-3 proteins exert critical control over membrane excitability, which constitutes the primary triggering event in ECC.

Until recently, their role in maintaining intracellular calcium homeostasis was associated mainly through the analysis in heterologous systems. However, the discovery that 14-3-3 proteins interact directly with phospholamban to

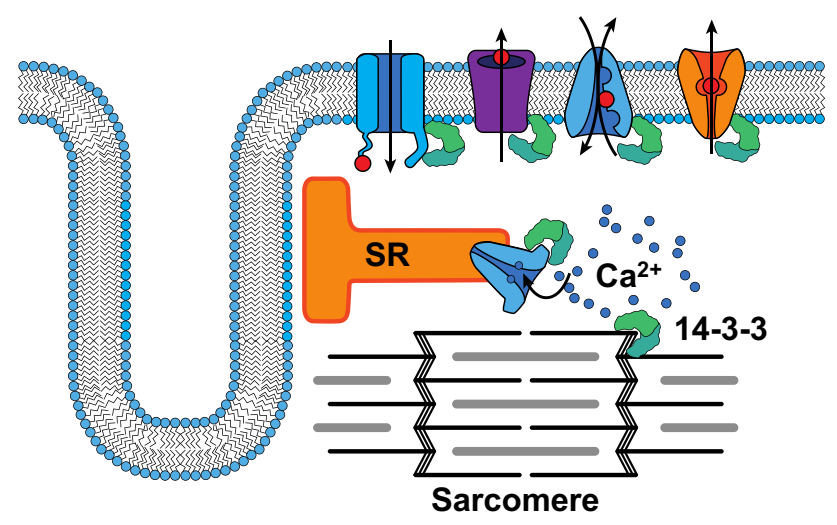

Fig. 2 Summary of the main $14-3-3$ and client protein interactions involved in the modulation of excitation-contraction coupling that have been identified to date. Specific aspects of client protein assembly into functional complexes are not depicted but are described in the text. ( 14-3-3 dimer; (1) voltage-gated channel carrying inward current (e.g., $\mathrm{Na}^{+}$channel); voltage-gated channel carrying outward currents (e.g., $\mathrm{K}^{+}$channel); cation exchanger (e.g., $\mathrm{Na}^{+} / \mathrm{Ca}^{2+}$ exchanger); electrogenic pump (e.g., $\mathrm{Ca}^{2+}$ ATPase); $\sqrt{ }$ sarco/endoplasmic reticulum $\mathrm{Ca}^{2+}$ ATPase) alter reuptake kinetics of $\mathrm{Ca}^{2+}$ into the sarcoplasmic reticulum within the cardiac myocyte represents the most direct mechanism to date and provides pivotal support to their role in ECC. PLN plays an important role in muscle in relaxation albeit to differing degrees between the muscle subtypes. Extending the 14-3-3/PLN interaction to the regulation of contractility places this mechanism at a critical nexus in ECC. Moreover, the suggestion that this mechanism may be causal in the development of dilated cardiomyopathy in patients that carry a mutation in the 14-3-3 binding motif in PLN may provide rationale for the development of 14-3-3 targeted therapeutic intervention using small molecular stabilizers such as fusicoccin-A or derivatives [31].

Finally, while the data implicating direct 14-3-3 protein interactions with the contractile machinery are evolving, a recent publication aimed at defining alpha-actinin interacting partners at the Z-disc of the sarcomere identified both 14-3$3 \varepsilon$ and $14-3-3 \gamma$ using a proximity-dependent biotinylation (BioID) approach in hiPSC-CM [35]. To our knowledge, this represents the first study that demonstrates a 14-3-3 protein contractile protein interaction, and broadly implicates their involvement in myofibrillar assembly and/or trafficking of accessory proteins to the myofibrils.

\section{Concluding remarks and future directions}

There is generally a greater understanding as to the functional significance of 14-3-3/client protein interactions in certain cellular processes and disease states. Undoubtedly, their role in the formation of signaling complexes, intracellular protein translocation, and protein trafficking of more than 200 client partners has rightly positioned them as important intracellular modulators [50]. Despite this recognition, the precise mechanisms of their interactions and composition of 14-3-3 dimers are still being elucidated, but as recognized in this review, answering these questions could have a significant influence on our understanding of ECC regulation and provide further therapeutic options for dysregulation of this critical process. To that end, new proteomic-based tools are being developed to better define the 14-3-3 protein interactome within different cell types, to quantify changes in these interactions in response to changes in the physiological and pathophysiological environment and help identify potential 14-3-3 binding domains. All bear brief mention as they are most applicable and would be useful for investigating the extent of 14-3-3 protein-protein interactions in ECC.

14-3-3 capture and release is an approach by which client proteins are captured via 14-3-3 affinity purification and eluted with a phosphopeptide analog corresponding to the mode I 14-3-3 binding domain consensus sequence (ARAApSAPA), for identification by mass spectrometry. As noted, this methodology first identified the breadth of 
Table 1 Identification of putative 14-3-3 binding sites in contractile and calcium handling proteins associated with ECC in human cardiac myocytes using the web-based 14-3-3 Pred tool (http://www. compbio.dundee.ac.uk/1433pred.). Protein name and UniProtKB ID (in brackets), plus all sites predicted (strong and weak scores) except where noted. Proteins absent from Table 1 due to no 14-3-3

\begin{tabular}{|c|c|c|c|}
\hline Myofilament proteins & 14-3-3-predicted sites & $\mathrm{Ca}^{2+}$ handling proteins & 14-3-3-predicted sites \\
\hline $\begin{array}{l}\text { TNNI3_Troponin I, cardiac muscle } \\
\text { (P19429) }\end{array}$ & $\begin{array}{l}\text { S23, S24, T31, S77, T143, S150, } \\
\text { S166, S210 }\end{array}$ & $\begin{array}{l}\text { AT2A2_Sarcoplasmic/endoplas- } \\
\text { mic reticulum calcium ATPase } 2 \\
\text { (P16615) }\end{array}$ & $\begin{array}{l}\text { S136, T172, S265, S493, S495, } \\
\text { S509, T847, S941, S973, } \\
\text { S1006 }\end{array}$ \\
\hline $\begin{array}{l}\text { TPM1_Tropomyosin alpha-1 chain } \\
\text { (P09493) }\end{array}$ & S247, S271 & $\begin{array}{l}\text { PPLA_Cardiac phospholamban } \\
\text { (P26678) }\end{array}$ & S16, T17 \\
\hline $\begin{array}{l}\text { MYPC3_Myosin-binding protein } \\
\text { C, cardiac type (Q14896) }\end{array}$ & $\begin{array}{l}\text { S242, S275, S284, S286, S304, } \\
\text { T498, T 688, T729, T1026, } \\
\text { S1040, S1141, T1153, T1184, } \\
\text { S1231 }\end{array}$ & $\begin{array}{l}\text { RYR2_HUMAN Ryanodine recep- } \\
\text { tor } 2 \text { (Q92736) }\end{array}$ & $\begin{array}{l}53 \text { sites-highest scored: T279, } \\
\text { T301, S742, T1466, S1662, } \\
\text { S0231, S2808, S3196, S4260, } \\
\text { S4539 }\end{array}$ \\
\hline MYH7_Myosin-7 (P12883) & $\begin{array}{l}\text { S111, S158, T446, T547, T665, } \\
\text { T786, S810, T971, S1362, S1366, } \\
\text { S1478, S1596, S1843, S1924 }\end{array}$ & $\begin{array}{l}\text { NAC1_Sodium/calcium exchanger } \\
1 \text { (P32418) }\end{array}$ & $\begin{array}{l}\text { S101, S285, S392, T621, T836, } \\
\text { T912 }\end{array}$ \\
\hline $\begin{array}{l}\text { ACTC_Actin alpha cardiac muscle } \\
1 \text { (P68032) }\end{array}$ & T91, S201, T262, S340 & $\begin{array}{l}\text { AT2B4_Plasma membrane } \\
\text { calcium-transporting ATPase } 4 \\
\text { (P23634) }\end{array}$ & $\begin{array}{l}\text { T60, T137, T315, S576, S590, } \\
\text { T696, S756, T1102 }\end{array}$ \\
\hline ACTN2_Alpha-actinin-2 (P35609) & $\begin{array}{l}\text { T57, T165, S291, T495, T564, } \\
\text { S596, S624, T799, S870 }\end{array}$ & $\begin{array}{l}\text { CAC1C_Voltage-dependent L-type } \\
\text { calcium channel subunit alpha-1C } \\
\text { (Q13936) }\end{array}$ & $\begin{array}{l}36 \text { sites-highest scored: S465, } \\
\text { T688, T1462, T1622, S1718, } \\
\text { S1879, T1953, S1975, S1981, } \\
\text { S2027, S2098 }\end{array}$ \\
\hline
\end{tabular}
and cardiac muscle (P63316), TNNT2_Troponin T, cardiac muscle diac muscle isoform (P10916), MYL7_Myosin regulatory light chain 2, atrial isoform (Q01449), MYL3_Myosin light chain 3 (P08590), MYL4_Myosin light chain 4 (P12829) predicted sites include as follows: TNNC1_Troponin C, slow skeletal (P45379), MYL2_Myosin regulatory light chain 2, ventricular/car- the 14-3-3 protein interactions [50]. Modifications of this approach by which differential capture of 14-3-3 protein clients through isotope incorporation of digested proteins have permitted quantification of 14-3-3 protein/client protein interactions in response to signal pathway activation [18]. Limitations however have been the use of the yeast 14-3-3 isoforms (BMH1 and BMH2) for affinity capture even though they correspond to mammalian orthologs, but they do not permit isoform-specific capture analysis. Also, the use of mode I 14-3-3 binding domain phophopeptide to elute proteins which may not compete for all 14-3-3/client protein interactions. Nevertheless, the repertoire of 14-3-3 client proteins defined to date has helped define their scope of function in several cellular processes and permitted the formation of databases and bioinformatic tools which can be leveraged to identify and better understand 14-3-3 protein function in ECC. Likewise, an exciting alternative is the application of tandem affinity purification (TAP), an epitope-tagging purification strategy to purify protein complexes followed by tandem mass spectrometry. Evolving this approach, a TAP transgenic mouse line that expresses 14-3$3 \zeta$ was developed and used to identify interacting proteins in various tissues in situ [3]. One of the advantages offered by isolating 14-3-3 isoform protein complexes from their physiological environment is the analysis of tissue-specific interactions that might not be otherwise present in heterologous cell cultures. Further adaptation of this methodology to drive cell-specific expression, and/or breeding onto a disease model background, could provide an integrated physiological analysis of 14-3-3 protein client protein interactions during disease progression. In addition to these methodological approaches, as mentioned bioinformatic and in silico prediction web-based resources provide access to a database and a prediction method, for identification of potential 14-3-3 binding motifs within client proteins, and are helpful resources to initiate investigation into targets of interest [44, 63]. Utilizing the web-based 14-3-3 Pred tool built as a prediction method to analyze and prioritize putative $14-3-3$ binding sites in $>2000$ potential interactor proteins, we analyzed the major human contractile and calcium handling proteins expressed in the heart. This tool confirms some of the pre-existing targets discussed herein, but also identifies relevant new targets that are yet to be explored in the context of 14-3-3 modulation of ECC (Table 1). Of note is the presence of some well-defined serine/threonine phosphorylation sites within the putative 14-3-3 binding motifs such as S23 and S24 in the N-terminus of cardiac troponin I which play a significant role in the myofilaments response to $\mathrm{Ca}^{2+}$.

In the context of further studies of 14-3-3 protein function in the field of ECC, many questions remain to be addressed. First, how to identify the physiologically relevant receptors and their regulation by $14-3-3$ protein modulation within the context of ECC regulation? This is a vital but understudied area despite strong data in heterologous systems showing 14-3-3 protein interactions with $\beta$-arrestin 
and its role in G-protein-coupled receptor signaling. Second, what role do 14-3-3 isoforms play in mediating different pathways and functional activity of downstream proteins in the pathogenesis of muscle diseases? Third, given the proclivity of 14-3-3 isoforms to form homodimers or heterodimers, but also function as monomers, does this enable them to fulfill specific roles in ECC? Fourth, what effects do 14-3-3 proteins exert on client proteins in the balance of phosphorylation and dephosphorylation of critical residues in the regulation of ECC? These may be challenging questions to purse in muscle due to the unique structure functional relationship of the multimeric protein assemblies involved in ECC, and the potential for multiple 14-3-3 interaction sites within a single protein. Nevertheless, one clear advantage to help tackle these questions related to the structural, temporal, and spatial regulation of 14-3-3/client protein interactions in the regulation by ECC is the welldefined physiological and biophysical readouts associated with each of aspect this process in muscle.

Abbreviations $\beta$-receptor: Beta adrenergic receptor; $\mathrm{CHO}$ : Chinese hamster ovary; COPI: Coat protein complex 1; DN-14-3-3: Dominant negative 14-3-3 protein; ECC: Excitation contraction coupling; ER: Endoplasmic reticulum; HeLa: Henrietta Lacks cervical cancer cells; HERG: Human ether-a-go-go gene; hiPSC-CM: Human-induced pluripotent stem cell-derived cardiac myocytes; HSP20: Heat shock protein 20; LQTS: Long QT syndrome; MEF2C: Myocytes-specific enhancer factor 2C; MLC: Myosin light chain; MLCK: Myosin light chain kinase; MLCP: Myosin light chain phosphatase; MYTP1: Myosin targeting phosphatase subunit 1; miRNA: MicroRNA; NCX: Sodium calcium exchanger; NE: Norepinephrine; NRVM: Neonatal rat ventricular myocytes; PKA: Protein kinase A; PLN: Phospholamban; PMCA: Plasma membrane calcium ATPase; SAMP8: Senescenceaccelerated mouse-prone 8; SERCA: Sarcoplasmic reticulum calcium ATPase; SITR2: Sirtuin 2; TAP: Tandem affinity purification; VSMC: Vascular smooth muscle cells; 3'UTR: 3 Prime untranslated region; P90RSK: P90 Ribosomal S6 kinase

Acknowledgements We would like to thank Christopher Solis, Ph.D., for his assistance drawing Fig. 2.

Funding This work was supported by NIH grant PO1 HL062426. The content is solely the responsibility of the authors and does not necessarily represent the official views of the National institutes of Health.

\section{Declarations}

Conflict of interest The authors declare no competing interests.

Open Access This article is licensed under a Creative Commons Attribution 4.0 International License, which permits use, sharing, adaptation, distribution and reproduction in any medium or format, as long as you give appropriate credit to the original author(s) and the source, provide a link to the Creative Commons licence, and indicate if changes were made. The images or other third party material in this article are included in the article's Creative Commons licence, unless indicated otherwise in a credit line to the material. If material is not included in the article's Creative Commons licence and your intended use is not permitted by statutory regulation or exceeds the permitted use, you will need to obtain permission directly from the copyright holder. To view a copy of this licence, visit http://creativecommons.org/licenses/by/4.0/.

\section{References}

1. Allouis M, Le Bouffant F, Wilders R, Péroz D, Schott JJ, Noireaud J, Le Marec H, Mérot J, Escande D, Baró I (2006) 14-3-3 is a regulator of the cardiac voltage-gated sodium channel Nav1.5. Circ Res 98(12):1538-46. https://doi.org/10.1161/01.RES.00002 29244.97497.2c

2. An SS, Askovich PS, Zarembinski TI, Ahn K, Peltier JM, von Rechenberg M, Sahasrabudhe S, Fredberg JJ (2011) A novel small molecule target in human airway smooth muscle for potential treatment of obstructive lung diseases: a staged highthroughput biophysical screening. Respir Res 12(1):8. https:// doi.org/10.1186/1465-9921-12-8

3. Angrand PO, Segura I, Völkel P, Ghidelli S, Terry R, Brajenovic M, Vintersten K, Klein R, Superti-Furga G, Drewes G, Kuster B, Bouwmeester T, Acker-Palmer A (2006) Transgenic mouse proteomics identifies new 14-3-3-associated proteins involved in cytoskeletal rearrangements and cell signaling. Mol Cell Proteomics 5(12):2211-2227. https://doi.org/10.1074/mcp.M6001 47-MCP200

4. Arakel EC, Brandenburg S, Uchida K, Zhang H, Lin YW, Kohl T, Schrul B, Sulkin MS, Efimov IR, Nichols CG, Lehnart SE, Schwappach B (2014) Tuning the electrical properties of the heart by differential trafficking of KATP ion channel complexes. J Cell Sci 127(Pt 9):2106-2119. https://doi.org/10.1242/jcs. 141440

5. Autieri MV (2004) Inducible expression of the signal transduction protein 14-3-3gamma in injured arteries and stimulated human vascular smooth muscle cells. Exp Mol Pathol 76(2):99-107. https://doi.org/10.1016/j.yexmp.2003.11.001

6. Autieri MV, Carbone CJ (1999) 14-3-3Gamma interacts with and is phosphorylated by multiple protein kinase $\mathrm{C}$ isoforms in PDGFstimulated human vascular smooth muscle cells. DNA Cell Biol 18(7):555-564. https://doi.org/10.1089/104454999315105

7. Autieri MV, Haines DS, Romanic AM, Ohlstein EH (1997) Expression of 14-3-3 gamma in injured arteries and growth factor- and cytokine-stimulated human vascular smooth muscle cells. Cell Growth Differ 7(11):1453-1460

8. Badodi S, Baruffaldi F, Ganassi M, Battini R, Molinari S (2015) Phosphorylation-dependent degradation of MEF2C contributes to regulate G2/M transition. Cell Cycle 14(10):1517-1528. https:// doi.org/10.1080/15384101.2015.1026519

9. Berg D, Holzmann C, Riess O (2003) 14-3-3 proteins in the nervous system. Nat Rev Neurosci 4:752-762. https://doi.org/10.1038/ nrn1197

10 Chang HC, Rubin GM (1997) 14-3-3 epsilon positively regulates Ras-mediated signaling in Drosophila. Genes Dev 11(9):1132-9. https://doi.org/10.1101/gad.11.9.1132

11. Cheah PS, Ramshaw HS, Thomas PQ, Toyo-Oka K, Xu X, Martin S, Coyle P, Guthridge MA, Stomski F, van den Buuse M, Wynshaw-Boris A, Lopez AF (2012 Apr) Schwarz QP (2012) Neurodevelopmental and neuropsychiatric behaviour defects arise from 14-3-3? deficiency. Mol Psychiatry 17(4):451-466. https:// doi.org/10.1038/mp.2011.158

12. Chen HP, He M, Xu YL, Huang QR, Zeng GH, Liu D (2007 Jul 12) Liao $Z P$ (2007) Anoxic preconditioning up-regulates 14-3-3 protein expression in neonatal rat cardiomyocytes through extracellular signal-regulated protein kinase 1/2. Life Sci 81(5):372379. https://doi.org/10.1016/j.1fs.2007.05.026 
13. Choe CU, Schulze-Bahr E, Neu A, Xu J, Zhu ZI, Sauter K, Bähring R, Priori S, Guicheney P, Mönnig G, Neapolitano C, Heidemann J, Clancy CE, Pongs O, Isbrandt D (2006) C-terminal HERG (LQT2) mutations disrupt IKr channel regulation through 14-3-3epsilon. Hum Mol Genet 15(19):2888-2902. https://doi. org $/ 10.1093 / \mathrm{hmg} / \mathrm{ddl} 230$

14. Clatot J, Hoshi M, Wan X, Liu H, Jain A, Shinlapawittayatorn K, Marionneau C, Ficker E, Ha T (2017) Deschênes I (2017) Voltage-gated sodium channels assemble and gate as dimers. Nat Commun 8(1):2077. https://doi.org/10.1038/s41467-017-02262-0

15. Coblitz B, Wu M, Shikano S, Li M (2006) C-terminal binding: an expanded repertoire and function of 14-3-3 proteins. FEBS Lett 580(6):1531-1535. https://doi.org/10.1016/j.febslet.2006.02.014

16. Deshmukh AS, Murgia M, Nagaraj N, Treebak JT, Cox J, Mann M (2015) Deep proteomics of mouse skeletal muscle enables quantitation of protein isoforms, metabolic pathways, and transcription factors. Mol Cell Proteomics 14(4):841-853. https://doi.org/10. 1074/mcp.M114.044222

17. Dreiza CM, Brophy CM, Komalavilas P, Furnish EJ, Joshi L, Pallero MA, Murphy-Ullrich JE, von Rechenberg M, Ho YS, Richardson B, Xu N, Zhen Y, Peltier JM, Panitch A (2005) Transducible heat shock protein 20 (HSP20) phosphopeptide alters cytoskeletal dynamics. FASEB J 19(2):261-263. https:// doi.org/10.1096/fj.04-2911fje

18. Dubois F, Vandermoere F, Gernez A, Murphy J, Toth R, Chen S, Geraghty KM, Morrice NA, MacKintosh C (2009) Differential 14-3-3 affinity capture reveals new downstream targets of phosphatidylinositol 3-kinase signaling. Mol Cell Proteomics 8(11):2487-2499. https://doi.org/10.1074/mcp.M8005 44-MCP200

19. Duncan G, Firth K, George V, Hoang MD, Staniforth A, Smith G, Denning C (2017) Drug-mediated shortening of action potentials in LQTS2 human induced pluripotent stem cellderived cardiomyocytes. Stem Cells Dev 26(23):1695-1705. https://doi.org/10.1089/scd.2017.0172

20. Fu H, Coburn J, Collier RJ (1993) The eukaryotic host factor that activates exoenzyme $\mathrm{S}$ of Pseudomonas aeruginosa is a member of the 14-3-3 protein family. Proc Natl Acad Sci U S A 90(6):2320-2324. https://doi.org/10.1073/pnas.90.6.2320

21. Fuller W, Eaton P, Bell JR, Shattock MJ (2004) Ischemiainduced phosphorylation of phospholemman directly activates rat cardiac Na/K-ATPase. FASEB J 18(1):197-199. https://doi. org/10.1096/fj.03-0213fje

22. Gittenberger-de Groot AC, Hoppenbrouwers T, Miquerol L, Kosaka Y, Poelmann RE, Wisse LJ, Yost HJ, Jongbloed MR, Deruiter MC, Brunelli L (2016) 14-3-3epsilon controls multiple developmental processes in the mouse heart. Dev Dyn 245(11):1107-1123. https://doi.org/10.1002/dvdy.24440

23. Golubnitschaja O, Moenkemann H, Kim K, Mozaffari MS (2003) DNA damage and expression of checkpoint genes p21(WAF1/CIP1) and 14-3-3 sigma in taurine-deficient cardiomyocytes. Biochem Pharmacol 66(3):511-517. https://doi. org/10.1016/s0006-2952(03)00285-5

24. Golubnitschaja O, Moenkemann H, Trog DB, Blom HJ, De Vriese AS (2006) Activation of genes inducing cell-cycle arrest and of increased DNA repair in the hearts of rats with early streptozotocin-induced diabetes mellitus. Med Sci Monit 12(2):BR68-74

25. Gurusamy N, Watanabe K, Ma M, Prakash P, Hirabayashi K, Zhang S, Muslin AJ, Kodama M, Aizawa Y (2006) Glycogen synthase kinase 3beta together with 14-3-3 protein regulates diabetic cardiomyopathy: effect of losartan and tempol. FEBS Lett 580(8):1932-1940. https://doi.org/10.1016/j.febslet.2006.02.056

26. Gurusamy N, Watanabe K, Ma M, Zhang S, Muslin AJ, Kodama M, Aizawa Y (2004) Dominant negative 14-3-3 promotes cardiomyocyte apoptosis in early stage of type I diabetes mellitus through activation of JNK. Biochem Biophys Res Commun 320(3):773-780. https://doi.org/10.1016/j.bbrc.2004.06.023

27. Haydon CE, Watt PW, Morrice N, Knebel A, Gaestel M, Cohen P (2002) Identification of a phosphorylation site on skeletal muscle myosin light chain kinase that becomes phosphorylated during muscle contraction. Arch Biochem Biophys 397(2):224-231. https://doi.org/10.1006/abbi.2001.2625

28. He M, Zhang J, Shao L, Huang Q, Chen J, Chen H, Chen X, Liu D, Luo Z (2006) Upregulation of 14-3-3 isoforms in acute rat myocardial injuries induced by burn and lipopolysaccharide. Clin Exp Pharmacol Physiol 33(4):374-380. https://doi.org/10.1111/j. 1440-1681.2006.04378.x

29. Johnson C, Crowther S, Stafford MJ, Campbell DG, Toth R, MacKintosh C (2010) Bioinformatic and experimental survey of 14-3-3-binding sites. Biochem J 427(1):69-78. https://doi.org/10. 1042/BJ20091834

30. Kagan A, Melman YF, Krumerman A, McDonald TV (2002) 14-3-3 amplifies and prolongs adrenergic stimulation of HERG K+ channel activity. EMBO J 21(8):1889-1898. https://doi.org/ 10.1093/emboj/21.8.1889

31. Kaplan A, Morquette B, Kroner A, Leong S, Madwar C, Sanz R, Banerjee SL, Antel J, Bisson N, David S, Fournier AE (2017) Small-molecule stabilization of 14-3-3 protein-protein interactions stimulates axon regeneration. Neuron 93(5):1082-1093.e5. https://doi.org/10.1016/j.neuron.2017.02.018

32. Kim DE, Cho CH, Sim KM, Kwon O, Hwang EM, Kim HW, Park JY (2019) 14-3-3? haploinsufficient mice display hyperactive and stress-sensitive behaviors. Exp Neurobiol 28(1):43-53. https://doi. org/10.5607/en.2019.28.1.43

33. Koga Y, Ikebe M (2008) A novel regulatory mechanism of myosin light chain phosphorylation via binding of 14-3-3 to myosin phosphatase. Mol Biol Cell 19(3):1062-1071. https://doi.org/10. 1091/mbc.e07-07-0668

34. Kosaka Y, Cieslik KA, Li L, Lezin G, Maguire CT, Saijoh Y, Toyo-oka K, Gambello MJ, Vatta M, Wynshaw-Boris A, Baldini A, Yost HJ, Brunelli L (2012) 14-3-3? plays a role in cardiac ventricular compaction by regulating the cardiomyocyte cell cycle. Mol Cell Biol 32(24):5089-5102. https://doi.org/10.1128/MCB. 00829-12

35. Ladha FA, Thakar K, Pettinato AM, Legere N, Ghahremani S, Cohn R, Romano R, Meredith E, Chen YS, Hinson JT (2021) Actinin BioID reveals sarcomere crosstalk with oxidative metabolism through interactions with IGF2BP2. Cell Rep 36(6):109512. https://doi.org/10.1016/j.celrep.2021.109512

36. Lau JM, Jin X, Ren J, Avery J, DeBosch BJ, Treskov I, Lupu TS, Kovacs A, Weinheimer C, Muslin AJ (2007) The 14-3-3tau phosphoserine-binding protein is required for cardiomyocyte survival. Mol Cell Biol 27(4):1455-1466. https://doi.org/10.1128/ MCB.01369-06

37 Li Y, Wu Y, Zhou Y (2006) Modulation of inactivation properties of CaV2.2 channels by 14-3-3 proteins. Neuron 51(6):755-71. https://doi.org/10.1016/j.neuron.2006.08.014

38. Liao W, Wang S, Han C, Zhang Y (2005) 14-3-3 proteins regulate glycogen synthase 3 beta phosphorylation and inhibit cardiomyocyte hypertrophy. FEBS J 272(8):1845-1854. https://doi.org/10. 1111/j.1742-4658.2005.04614.x

39. Linde CI, Di Leva F, Domi T, Tosatto SC, Brini M, Carafoli E (2008) Inhibitory interaction of the 14-3-3 proteins with ubiquitous (PMCA1) and tissue-specific (PMCA3) isoforms of the plasma membrane Ca2+ pump. Cell Calcium 43(6):550-561. https://doi.org/10.1016/j.ceca.2007.09.003

40. Liu F, Zhou Q, Zhou J, Sun H, Wang Y, Zou X, Feng L, Hou Z, Zhou A, Zhou Y, Li Y (2015) 14-3-3? promotes surface expression of Cav2.2 (?1B) Ca2+ channels. J Biol Chem 290(5):268998. https://doi.org/10.1074/jbc.M114.567800 
41. Luk SC, Ngai SM, Tsui SK, Chan KK, Fung KP, Lee CY, Waye MM (1998) Developmental regulation of 14-3-3 epsilon isoform in rat heart. J Cell Biochem 68(2):195-199. https://doi.org/10. 1002/(sici)1097-4644(19980201)68:2\%3c195::aid-jcb6\%3e3.0. co;2-q

42. Lynn EG, McLeod CJ, Gordon JP, Bao J, Sack MN (2008) SIRT2 is a negative regulator of anoxia-reoxygenation tolerance via regulation of $14-3-3$ zeta and BAD in H9c 2 cells. FEBS Lett 582(19):2857-2862. https://doi.org/10.1016/j.febslet.2008.07.016

43. Mackintosh C (2004) Dynamic interactions between 14-3-3 proteins and phosphoproteins regulate diverse cellular processes. Biochem J 381(Pt 2):329-342. https://doi.org/10.1042/BJ20031332

44. Madeira F, Tinti M, Murugesan G, Berrett E, Stafford M, Toth R, Cole C, MacKintosh C, Barton GJ (2015) 14-3-3-Pred: improved methods to predict 14-3-3-binding phosphopeptides. Bioinformatics 31(14):2276-2283. https://doi.org/10.1093/bioinformatics/ btv133

45. Maekawa N, Abe J, Shishido T, Itoh S, Ding B, Sharma VK, Sheu SS, Blaxall BC, Berk BC (2006) Inhibiting p90 ribosomal S6 kinase prevents $(\mathrm{Na}+)-\mathrm{H}+$ exchanger-mediated cardiac ischemiareperfusion injury. Circulation 113(21):2516-2523. https://doi. org/10.1161/CIRCULATIONAHA.105.563486

46. Menzel J, Kownatzki-Danger D, Tokar S, Ballone A, UnthanFechner K, Kilisch M, Lenz C, Urlaub H, Mori M, Ottmann C, Shattock MJ, Lehnart SE, Schwappach B (2020) 14-3-3 binding creates a memory of kinase action by stabilizing the modified state of phospholamban. Sci Signal 13(647):eaaz1436. https://doi.org/ 10.1126/scisignal.aaz1436

47. Obsil T, Obsilova V (2011) Structural basis of 14-3-3 protein functions. Semin Cell Dev Biol 22(7):663-672. https://doi.org/ 10.1016/j.semcdb.2011.09.001

48. Obsilova V, Herman P, Vecer J, Sulc M, Teisinger J, Obsil T (2004) 14-3-3zeta C-terminal stretch changes its conformation upon ligand binding and phosphorylation at Thr232. J Biol Chem 279:4531-4540. https://doi.org/10.1074/jbc.M306939200

49. Pipkin W, Johnson JA, Creazzo TL, Burch J, Komalavilas P, Brophy C (2003) Localization, macromolecular associations, and function of the small heat shock-related protein HSP20 in rat heart. Circulation 107(3):469-476. https://doi.org/10.1161/01.cir. $0000044386.27444 .5 \mathrm{a}$

50. Pozuelo Rubio M, Geraghty KM, Wong BH, Wood NT, Campbell DG, Morrice N, Mackintosh C (2004) 14-3-3-affinity purification of over 200 human phosphoproteins reveals new links to regulation of cellular metabolism, proliferation and trafficking. Biochem J 379(Pt 2):395-408. https://doi.org/10.1042/BJ20031797

51. Pulina MV, Rizzuto R, Brini M, Carafoli E (2006) Inhibitory interaction of the plasma membrane $\mathrm{Na}+/ \mathrm{Ca} 2+$ exchangers with the 14-3-3 proteins. J Biol Chem 281(28):19645-19654. https://doi. org/10.1074/jbc.M602033200

52. Rimessi A, Coletto L, Pinton P, Rizzuto R, Brini M, Carafoli E (2005) Inhibitory interaction of the 14-3-3 \{epsilon\} protein with isoform 4 of the plasma membrane $\mathrm{Ca}(2+)$-ATPase pump. J Biol Chem 280(44):37195-203. https://doi.org/10.1074/jbc.M5049 21200

53. Rosenquist M, Sehnke P, Ferl RJ, Sommarin M, Larsson C (2000) Evolution of the 14-3-3 protein family: does the large number of isoforms in multicellular organisms reflect functional specificity? J Mol Evol 51(5):446-458. https://doi.org/10.1007/s002390010 107

54. Sari FR, Watanabe K, Thandavarayan RA, Harima M, Zhang S, Muslin AJ, Kodama M, Aizawa Y (2010) 14-3-3 protein protects against cardiac endoplasmic reticulum stress (ERS) and ERSinitiated apoptosis in experimental diabetes. J Pharmacol Sci 113(4):325-334. https://doi.org/10.1254/jphs.10047fp

55. Sluchanko NN, Artemova NV, Sudnitsyna MV, Safenkova IV, Antson AA, Levitsky DI, Gusev NB (2012) Monomeric 14-3-3? has a chaperone-like activity and is stabilized by phosphorylated HspB6. Biochemistry 51(31):6127-6138. https://doi.org/10.1021/ bi300674e

56. Smith AJ, Daut J, Schwappach B (2011) Membrane proteins as 14-3-3 clients in functional regulation and intracellular transport. Physiology (Bethesda) 26(3):181-191. https://doi.org/10.1152/ physiol.00042.2010

57. Sreedhar R, Giridharan VV, Arumugam S, Karuppagounder V, Palaniyandi SS, Krishnamurthy P, Quevedo J, Watanabe K, Konishi T, Thandavarayan RA (2016) Role of MAPK-mediated endoplasmic reticulum stress signaling in the heart during aging in senescence-accelerated prone mice. BioFactors 42(4):368-375. https://doi.org/10.1002/biof.1280

58. Steinacker P, Schwarz P, Reim K, Brechlin P, Jahn O, Kratzin H, Aitken A, Wiltfang J, Aguzzi A, Bahn E, Baxter HC, Brose N, Otto M (2005) Unchanged survival rates of 14-3-3gamma knockout mice after inoculation with pathological prion protein. Mol Cell Biol 25(4):1339-1346. https://doi.org/10.1128/MCB.25.4. 1339-1346.2005

59. Stevers LM, Sijbesma E, Botta M, MacKintosh C, Obsil T, Landrieu I, Cau Y, Wilson AJ, Karawajczyk A, Eickhoff J, Davis J, Hann M, O’Mahony G, Doveston RG, Brunsveld L, Ottmann C (2018) Modulators of 14-3-3 protein-protein interactions. J Med Chem 61(9):3755-3778. https://doi.org/10.1021/acs.jmedchem. $7 \mathrm{~b} 00574$

60. Sun H, Li M, Gong L, Liu M, Ding F, Gu X (2012) iTRAQcoupled 2D LC-MS/MS analysis on differentially expressed proteins in denervated tibialis anterior muscle of Rattus norvegicus. Mol Cell Biochem 364(1-2):193-207. https://doi.org/10.1007/ s11010-011-1218-2

61. Tang Z, Qiu H, Luo L, Liu N, Zhong J, Kang K, Gou D (2017) miR-34b modulates skeletal muscle cell proliferation and differentiation. J Cell Biochem 18(12):4285-4295. https://doi.org/10. $1002 / j \mathrm{jcb} .26079$

62. Thandavarayan RA, Giridharan VV, Sari FR, Arumugam S, Veeraveedu PT, Pandian GN, Palaniyandi SS, Ma M, Suzuki K, Gurusamy N, Watanabe K (2011) Depletion of 14-3-3 protein exacerbates cardiac oxidative stress, inflammation and remodeling process via modulation of MAPK/NF- $\mathrm{B}$ signaling pathways after streptozotocin-induced diabetes mellitus. Cell Physiol Biochem 28(5):911-922. https://doi.org/10.1159/000335805

63 Tinti M, Madeira F, Murugesan G, Hoxhaj G, Toth R, Mackintosh C (2014) ANIA: ANnotation and Integrated Analysis of the 14-3-3 interactome. Database (Oxford) 2014:bat085. https://doi. org/10.1093/database/bat085

64. Toyo-oka K, Shionoya A, Gambello MJ, Cardoso C, Leventer R, Ward HL, Ayala R, Tsai LH, Dobyns W, Ledbetter D, Hirotsune S, Wynshaw-Boris A (2003) 14-3-3epsilon is important for neuronal migration by binding to NUDEL: a molecular explanation for Miller-Dieker syndrome. Nat Genet 34(3):274-285. https:// doi.org/10.1038/ng1169

65. Tutor AS, Delpón E, Caballero R, Gómez R, Núñez L, Vaquero M, Tamargo J, Mayor F Jr, Penela P (2006) Association of 14-3-3 proteins to beta1-adrenergic receptors modulates Kv11.1 $\mathrm{K}+$ channel activity in recombinant systems. Mol Biol Cell 17(11):4666-74. https://doi.org/10.1091/mbc.e06-05-0422

66. Utrilla RG, Nieto-Marín P, Alfayate S, Tinaquero D, Matamoros M, Pérez-Hernández M, Sacristán S, Ondo L, de Andrés R, DíezGuerra FJ, Tamargo J, Delpón E, Caballero R (2017) Kir2.1Nav1.5 channel complexes are differently regulated than Kir2.1 and Nav1.5 channels alone. Front Physiol 8:903. https://doi.org/ 10.3389/fphys.2017.00903

67. Vafiadaki E, Arvanitis DA, Eliopoulos AG, Kranias EG, Sanoudou D (2020) The cardioprotective PKA-mediated Hsp20 phosphorylation modulates protein associations regulating cytoskeletal 
dynamics. Int J Mol Sci 21(24):9572. https://doi.org/10.3390/ ijms 21249572

68. Watanabe K, Ma M, Hirabayashi K, Gurusamy N, Veeraveedu PT, Prakash P, Zhang S, Muslin AJ, Kodama M, Aizawa Y (2007) Swimming stress in DN 14-3-3 mice triggers maladaptive cardiac remodeling: role of p38 MAPK. Am J Physiol Heart Circ Physiol 292(3):H1269-H1277. https://doi.org/10.1152/ajpheart.00550. 2006

69. West-Foyle H, Kothari P, Osborne J, Robinson DN (2018) 14-3-3 proteins tune non-muscle myosin II assembly. J Biol Chem 293(18):6751-6761. https://doi.org/10.1074/jbc.M117.819391

70. Xing H, Zhang S, Weinheimer C, Kovacs A, Muslin AJ (2000) 14-3-3 proteins block apoptosis and differentially regulate MAPK cascades. EMBO J 19(3):349-358. https://doi.org/10.1093/emboj/ 19.3.349

71. Yaffe MB (2002) How do 14-3-3 proteins work?-Gatekeeper phosphorylation and the molecular anvil hypothesis. FEBS Lett 513(1):53-57. https://doi.org/10.1016/s0014-5793(01)03288-4

72. Yaffe MB, Rittinger K, Volinia S, Caron PR, Aitken A, Leffers H, Gamblin SJ, Smerdon SJ, Cantley LC (1997) The structural basis for 14-3-3:phosphopeptide binding specificity. Cell 91(7):961971. https://doi.org/10.1016/s0092-8674(00)80487-0
73. Yang X, Lee WH, Sobott F, Papagrigoriou E, Robinson CV, Grossmann JG, Sundström M, Doyle DA, Elkins JM (2006) Structural basis for protein-protein interactions in the 14-3-3 protein family. Proc Natl Acad Sci U S A 103(46):17237-17242. https:// doi.org/10.1073/pnas.0605779103

74. Yohannes E, Chang J, Tar MT, Davies KP, Chance MR (2010) Molecular targets for diabetes mellitus-associated erectile dysfunction. Mol Cell Proteomics 9(3):565-578. https://doi.org/10. 1074/mcp.M900286-MCP200

75. Zhang S, Ren J, Zhang CE, Treskov I, Wang Y, Muslin AJ (2003) Role of 14-3-3-mediated p38 mitogen-activated protein kinase inhibition in cardiac myocyte survival. Circ Res 93(11):10261028. https://doi.org/10.1161/01.RES.0000104084.88317.91

76. Zhou J, Shin HG, Yi J, Shen W, Williams CP, Murray KT (2002) Phosphorylation and putative ER retention signals are required for protein kinase A-mediated potentiation of cardiac sodium current. Circ Res 91(6):540-546. https://doi.org/10.1161/01.res. 0000033598.00903 .27

Publisher's note Springer Nature remains neutral with regard to jurisdictional claims in published maps and institutional affiliations. 